\title{
Poly(arylene ether) anion exchange membranes based on phenolphthalein derivatives for alkaline fuel cells
}

\author{
Nobuo Hara ${ }^{1,2}$, Chang Hyun Lee ${ }^{1,3}$, James E. McGrath ${ }^{1 *}$ \\ *1) Department of Chemistry, Macromolecules and Interfaces Institute, Virginia Polytechnic Institute and State University, \\ Blacksburg, VA 24061, USA. Fax: +01-540-231-8517, e-mail: jmcgrath@vt.edu \\ 2) (Current Affiliation) Research Institute for Innovation in Sustainable Chemistry, National Institute of Advanced Industrial \\ Science and Technology (AIST), Central 5, 1-1-1 Higashi, Tsukuba, Ibaraki 305-8565, JAPAN. Fax: 81-29-861-4457, e-mail: \\ n-hara@aist.go.jp \\ 3) (Current Affiliation) Energy engineering, College of engineering, Dankook university, Cheonan 330-717, Korea. \\ Fax:+82-10-4250-6547, e-mail: chlee@dankook.ac.kr
}

\begin{abstract}
Anion exchange membranes for alkaline fuel cells based on phenolphthalein derivatives were prepared. First, phenolphthalein was derivatized with N,N,-dimethyl-1,3-propanediamine (DMPDA) and N,N,-dimethyl-1,2-ethanediamine (DMEDA). Copolymers containing DMPDA and DMEDA were then prepared via step-condensation or polycondensation polymerization using 4,4'-dichlorodiphenylsulfone or 2,6-dichlorobenzonitrile as an activated dihalide. These copolymers were first solution cast and then reacted with methyl iodide to generate quaternary ammonium groups. The new anion exchange membranes showed high anion conductivity of $>10$ $\mathrm{mS} / \mathrm{cm}$ at $30{ }^{\circ} \mathrm{C}$. Thorough investigation of the chemical stability of the copolymers under basic conditions indicated that DMPDA-containing copolymers showed higher stability than DMEDA-containing copolymers. The relationship between the chemical structure and stability was systematically studied.

Key words: Alkaline fuel cells, Anion exchange membrane, Phenolphthalein, Conductivity, Quaternary ammonium group.
\end{abstract}

\section{Introduction}

Fuel cells are recognized as important future alternative energy candidates because of their high efficiency and low environmental impact. ${ }^{1}$ Among all the fuel cells, proton exchange membrane fuel cells (PEMFCs) are the most developed ones. ${ }^{2}$ However, PEMFCs face significant problems such as high cost of proton exchange membranes (PEMs) and platinum catalyst. Recently, alkaline fuel cells (AFCs) have also been recognized as viable future energy candidates. ${ }^{3}$ Alkaline exchange membranes (AEMs) are used in AFCs, and the internal cell environment is maintained at a high $\mathrm{pH}$. The oxygen reduction reaction at the cathode is more facile under basic conditions and a wide variety of non-platinum metal catalysts such as nickel and cobalt can be employed, which in turn will enable the use of a large variety of fuels. ${ }^{4}$ In addition to these low-cost catalysts, liquid fuels afford easy storage, thereby providing another advantage for their applications in automobiles. ${ }^{5}$

The most important requirements for AEMs are high anionic conductivity and chemical durability under high $\mathrm{pH}$ conditions. Most of the previous research was based on the chloromethylation and quaternization of benzyl chloromethyl groups. Polystyrene-based copolymers have already been proposed, ${ }^{6}$ and radiation-grafted fluorinated copolymers have been developed and applied for fuel cell operations. However, the chemical durability of the electrolyte membranes is a major problem. ${ }^{7,8}$ Chemically stable aromatic copolymers have also been employed for AEMs. They include polysulfone-based copolymers, ${ }^{9-11}$ polysulfone-based copolymers cross-linked with diamine, ${ }^{12}$ poly(phenylene oxide) ${ }^{13}, \quad{ }^{14}$ poly(phthalazinone ether ketone) ${ }^{15}$ poly(imide), ${ }^{16}$ and fluorenyl-containing copolymers. ${ }^{17}$ In addition to chloromethylation, the bromination and quaternization of benzyl methyl groups on poly(sulfone)s have been reported. ${ }^{18}$

Until now, the AEM research has primarily focused on improving the ionic conductivity. Unfortunately, their chemical stabilities are not strong enough to endure the alkaline environment. The suggested degradation mechanisms of anionic functional groups in the alkaline environment are: 1) direct nucleophilic displacement mechanism by hydroxide ions and 2) Hofmann elimination mechanism when $\beta$-protons are present. ${ }^{19,20}$ Although the chemical structure and durability are closely related, their relationship has not been clearly defined.

This paper describes the synthesis of new aromatic anion exchange copolymers with a poly(arylene ether) backbone based on phenolphthalein (PPH) derivatives. PPH is a bulky monomer and often used to introduce side functional groups into copolymers. ${ }^{21} \mathrm{PPH}$ was derivatized with $\mathrm{N}, \mathrm{N}$,-dimethyl-1,3-propanediamine (DMPDA) and N,N,-dimethyl-1,2-ethanediamine (DMEDA). Copolymers containing DMPDA and DMEDA were then prepared via step-condensation or polycondensation polymerization using 4,4'-dichloro diphenylsulfone (DCDPS) or 2,6-dichloro-benzonitrile (DCBN) as the activated dihalide monomers. The relationship between the properties and chemical stability of PPH-based anion exchange membranes were systematically studied. 


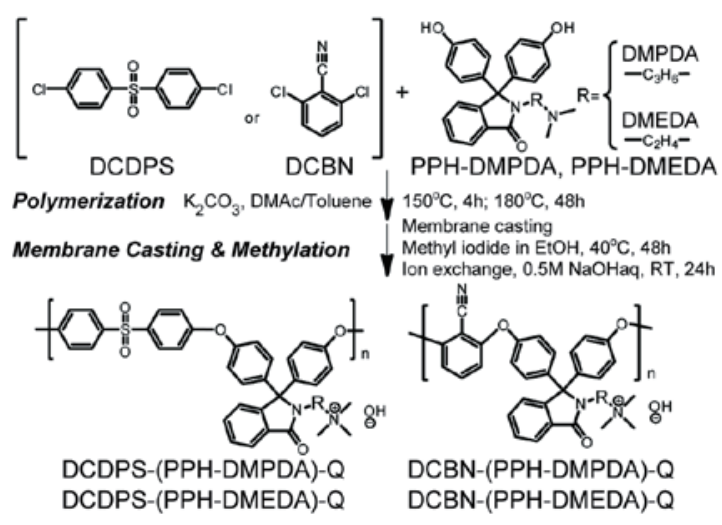

Fig.1 Synthesis scheme and chemical structures of copolymers based on phenolphthalein derivatives.

\section{Experimental}

PPH, DMPDA, DMEDA, potassium carbonate, toluene, methyl iodide, ethanol, and sodium hydroxide were purchased from Aldrich and used as received. DCDPS was provided by Solvay Advanced Polymers, and DCBN was purchased from Tokyo Chemical Industry Co., Ltd. DCDPS and DCBN were used after vacuum drying at $80{ }^{\circ} \mathrm{C}$ for $24 \mathrm{~h}$. N,N-dimethyl acetamide (DMAc) was purchased from Aldrich and was vacuum-distilled from calcium hydride and collected over activated molecular sieves.

For PPH-DMPDA monomer, $80 \mathrm{~g}$ of PPH and $130 \mathrm{~g}$ of DMPDA were charged in a 500-ml round flask. The mixture was stirred and refluxed at $140{ }^{\circ} \mathrm{C}$ for $24 \mathrm{~h}$. The reaction mixture was poured into ice water, and neutralized with hydrochloric acid. The precipitate was filtered, washed with deionized (DI) water, and recrystallized from a mixture of ethanol and DI water. The obtained white powder was vacuum dried at $80{ }^{\circ} \mathrm{C}$ for $24 \mathrm{~h}$. For PPH-DMEDA monomer, $80 \mathrm{~g}$ of PPH and $120 \mathrm{~g}$ of DMEDA were used and refluxed at $110^{\circ} \mathrm{C}$ for $24 \mathrm{~h}$ and purified.

The copolymers were successfully synthesized via aromatic nucleophilic substitution step copolymerization (Fig.1). One typical procedure considered for DCDPS-(PPH-DMPDA) is as follows: DCDPS (4.05 g, $14.1 \mathrm{mmol})$, PPH-DMPDA (5.46 g, $14.1 \mathrm{mmol})$, and potassium carbonate $(2.24 \mathrm{~g}, 16.2 \mathrm{mmol})$ were charged to a $300-\mathrm{ml}$ three-neck flask equipped with a mechanical stirrer, nitrogen inlet, and a Dean-Stark trap. Dry DMAc ( $60 \mathrm{ml}$ ) was introduced in the flask to provide $\sim 15 \mathrm{wt} \%$ solid concentration; toluene $(20 \mathrm{ml})$ was introduced as an azeotropic agent. The reaction mixture was heated under reflux at $150{ }^{\circ} \mathrm{C}$ for $4 \mathrm{~h}$ to remove any water. Then, the bath temperature was gradually raised to $180{ }^{\circ} \mathrm{C}$ and the polymerization reaction was carried out for an additional $48 \mathrm{~h}$. The copolymer solution was isolated by precipitation in DI water, washed several times with DI water and methanol, and dried in a vacuum oven at $80{ }^{\circ} \mathrm{C}$ for $24 \mathrm{~h}$. For DCBN-containing copolymers, polymerization was conducted at $170{ }^{\circ} \mathrm{C}$.

The copolymers were redissolved in DMAc to obtain a transparent $5 \mathrm{wt} \%$ solution, and then cast onto a clean glass plate. The prepared membranes were gradually dried for $24 \mathrm{~h}$ with infrared radiation and then dried under vacuum. The membranes were quaternized with $10 \mathrm{wt} \%$ methyl iodide solution in ethanol at $40{ }^{\circ} \mathrm{C}$ for 48 h. The obtained membranes were treated with $0.5 \mathrm{M}$
$\mathrm{NaOH}$ aqueous solution at room temperature for $24 \mathrm{~h}$, and then washed and stored in DI water.

${ }^{1} \mathrm{H}-\mathrm{NMR}$ analysis was conducted on a Varian Unity 400 spectrometer. All spectra were obtained from deuterated dimethyl sulfoxide (DMSO-d6) solutions at room temperature. Gel permeation chromatography (GPC) experiments were performed at $60{ }^{\circ} \mathrm{C}$ with N-Methyl-2-pyrrolidone (NMP) containing $0.05 \mathrm{M}$ lithium bromide. The molecular weights were determined by universal calibration with polystyrene standards.

The water uptake of the membranes was gravimetrically determined. The membranes were placed in DI water for $24 \mathrm{~h}$ before measurement. Wet membranes were removed from the liquid water, blotted dry to remove any surface droplets, and quickly weighed. The membranes were then dried at $120{ }^{\circ} \mathrm{C}$ under vacuum for at least $24 \mathrm{~h}$ to measure weight. The water uptake of the membranes was calculated according to the following equation:

$$
\text { Water uptake }(\%)=\frac{W_{\text {wet }}-W_{d r y}}{W_{d r y}} \times 100,
$$

where $W_{\text {wet }}$ and $W_{d r y}$ are the mass of wet and dry samples, respectively.

In-plane membrane conductivity in the fully hydrated state was measured at temperature range $30-60{ }^{\circ} \mathrm{C}$ using a Solartron 1252 Impedance Analyzer. The membranes were cut (dimensions $=4 \mathrm{~cm} \times 1 \mathrm{~cm})$ and soaked in DI water at room temperature for $24 \mathrm{~h}$ prior to the measurements. Anionic conductivity was obtained using the following equation:

$$
\sigma(S / \mathrm{cm})=\frac{L}{R S},
$$

where $L$ is the distance between the reference electrodes, $R$ is the electric resistance of the membrane, and $S$ is the cross-section area of the membrane.

\section{Results and Discussion}

3.1 Monomer and polymer syntheses

Two types of PPH-based monomers, PPH-DMPDA and PPH-DMEDA, were successfully synthesized, and their chemical structures were confirmed from the ${ }^{1} \mathrm{H}-\mathrm{NMR}$ measurements. The copolymers were successfully prepared from the reaction scheme shown in Fig.1, and the chemical structures were confirmed from ${ }^{1} \mathrm{H}-\mathrm{NMR}$. The calculation using the integration values of proton peaks confirmed that these copolymers contain theoretical amount of tertiary amine groups. The average molecular weight of each obtained copolymers was $>30,000$. The solution casting formed tough and transparent membranes with thicknesses $\sim 50 \mu \mathrm{m}$.

\subsection{Membrane characterization}

The prepared membranes were then immersed in methyl iodide solution in ethanol for $48 \mathrm{~h}$, and the tertiary amine groups were converted to quaternary ammonium groups. Their chemical structures were also confirmed from ${ }^{1} \mathrm{H}-\mathrm{NMR}$ measurements, as shown in Fig.2. For the copolymers containing PPH-DMPDA, the proton peak $i$, assigned to the methyl group, shifted from 1.9 to $2.9 \mathrm{ppm}$ after methylation, and the integration values of the peak increased. Thus, the tertiary amine 


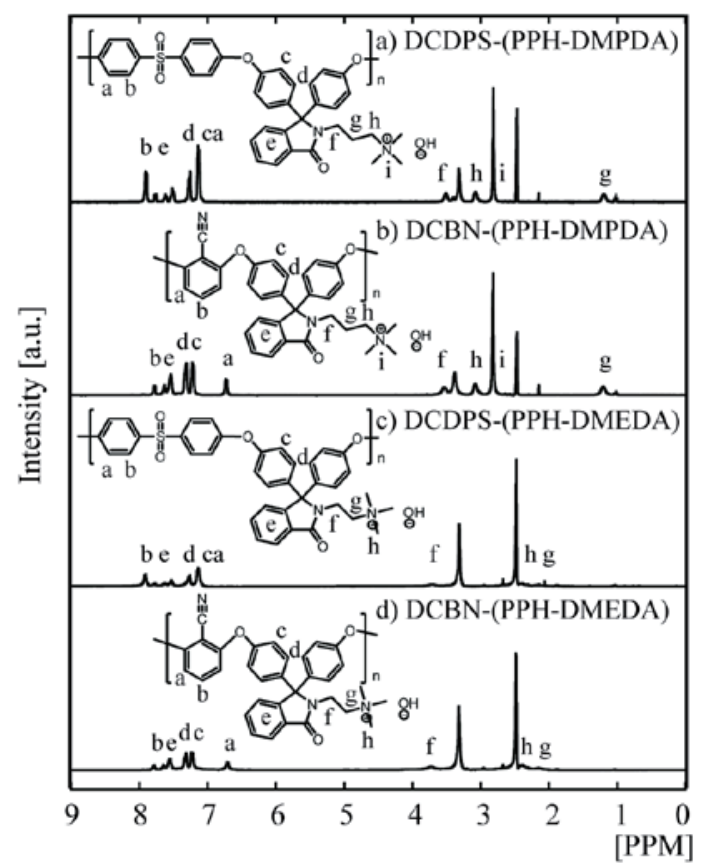

Fig. $2{ }^{1} \mathrm{H}-\mathrm{NMR}$ spectra of obtained copolymers.

groups were successfully converted to quaternary ammonium groups, and the conversion values of $>95 \mathrm{~mol} \%$ were calculated from the integration values of the peak $i$.

In PPH-DMEDA-containing copolymers, the proton peak $h$, assigned to the methyl group, shifted from 1.9 to $2.5 \mathrm{ppm}$. Thus, the tertiary ammonium groups were also successfully converted to quaternary ammonium groups. However, a certain amount of these quaternary ammonium groups degraded as the intensity of the proton peak $h$ assigned to the methyl group decreased.

The ion exchange capacity (IEC) values were theoretically calculated from the ${ }^{1} \mathrm{H}-\mathrm{NMR}$ measurements for the PPH-DMPDA-containing copolymers, and the values were $2.0 \mathrm{meq} / \mathrm{g}$ and 1.6 $\mathrm{meq} / \mathrm{g}$ for DCDPS-(PPH-DMPDA)-Q and DCBN-(PPH-DMPDA)-Q, respectively; Q denotes the quaternary ammonium groups. The water uptake of $\sim 20 \%$ was obtained for both DCDPS-(PPH-DMPDA)-Q and DCBN-(PPH-DMPDA)-Q. However, the IEC values for the PPH-DMEDA-containing copolymers were uncertain because of the continuous degradation of the quaternary ammonium groups. The water uptake values were less than $10 \%$. This degradation was observed over 1-2 days.

\subsection{Anionic conductivity}

Anionic conductivity obtained using alternative current impedance spectroscopic method is shown in Fig.3. The conductivity of DCDPS-(PPH- DMPDA)-Q and DCBN-(PPH-DMPDA)-Q at $30{ }^{\circ} \mathrm{C}$ was $9.4 \mathrm{mS} / \mathrm{cm}$ and $8.9 \mathrm{mS} / \mathrm{cm}$, respectively. Anionic conductivity increased at the elevated temperatures (Fig.3). The conductivity reached at $14 \mathrm{mS} / \mathrm{cm}$ and $13 \mathrm{mS} / \mathrm{cm}$ for the DCDPS-(PPH-DMPDA)-Q and the DCBN-(PPHDMPDA)-Q at $60{ }^{\circ} \mathrm{C}$, respectively. Meanwhile, the conductivity of the PPH-DMEDA-containing copolymers were less than $10^{-4} \mathrm{~S} / \mathrm{cm}$, which can result

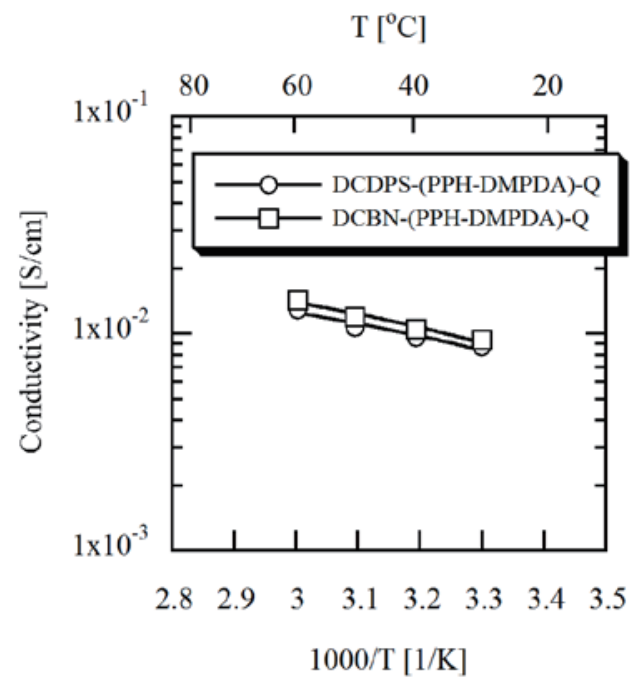

Fig.3 Anionic conductivity of DCDPS-(PPH-DMPDA)$\mathrm{Q}$ and DCBN-(PPH DMPDS)-Q membranes.

from the chemical degradation.

The activation energy of anionic conductivity was obtained from the Arrhenius plot (Fig.3) using the following equation:

$$
\sigma=\sigma_{0} \exp \left(-\frac{E_{a}}{R T}\right),
$$

where $\sigma_{0}$ is a pre-exponential factor, $E_{a}$ is the activation energy of anionic conductivity, $R$ is the universal gas constant, and $T$ is the temperature.

The activation energy for DCDPS-(PPH-DMPDA)-Q and DCBN-(PPH-DMPDA)-Q was $11.6 \mathrm{~kJ} / \mathrm{mol}$ and 10.8 $\mathrm{kJ} / \mathrm{mol}$, respectively. The activation energy of AEMs reported so far is within the range $12-25 \mathrm{~kJ} / \mathrm{mol}$. These values are much higher than those of PEMs $(\sim 9 \mathrm{~kJ} / \mathrm{mol})$ owing to the low ionic mobility of bicarbonate conducting counter-ion. ${ }^{18,22}$ On the other hand, the activation energies of the PPH derivative copolymers are comparable to that of PEMs, indicating that the bicarbonate possesses a small amount of anionic counter-ions in those membranes.

\subsection{Degradation analysis}

The chemical degradation of PPH was precisely analyzed to determine its mechanism. The quaternized membranes were immersed into $0.5 \mathrm{M} \mathrm{NaOH}$ aqueous solution at $25^{\circ} \mathrm{C}$ immediately after quaternization, and the change in the chemical structure was analyzed after 1 and 2 days using ${ }^{1} \mathrm{H}-\mathrm{NMR}$ in DMSO-d6. The number of protons assigned to the methyl groups of the quaternary ammonium groups for a single $\mathrm{PPH}$ unit structure was calculated from the following equation:

$$
\text { Number of protons }=\frac{4 i}{d}, \frac{4 h}{d},
$$

where $d, i$ and $h$ are the integration values of the proton peaks shown in Fig.2.

The PPH-DMPDA-containing copolymers had almost nine protons immediately after methylation, which meant that the tertiary amine was almost completely quaternized. After the degradation test, the number of protons decreased by $8 \%$ for DCDPS-(PPH-DMPDA)-Q and $15 \%$ for DCBN-(PPH-DMPDA)-Q. Moreover, 
DCDPS-(PPH-DMPDA)-Q showed higher durability than DCBN-(PPH-DMPDA)-Q. For the DMEDAcontaining copolymers, the proton peak of the quaternary ammonium groups shifted up-field after the degradation test. After 2 days of the degradation test, the number of protons decreased by $\sim 75 \%$ for DCDPS(PPH-DMEDA)-Q and $\sim 60 \%$ for DCBN-(PPHDMEDA)-Q. This meant that the quaternized ammonium groups were completely damaged in the degradation test. The observed degradation was the cause for low water uptakes and low conductivity of the PPH-DMEDA-containing copolymers. Moreover, the degradations were caused by the Hofmann elimination and direct nucleophilic substitution mechanisms, as reported previously. ${ }^{19}, 20$ The Hofmann elimination mechanism seemed to be dominant with the PPH-DMPDA-containing copolymers while the direct nucleophilic substitution mechanism was dominant in the PPH-DMEDA-containing copolymers. Thus, in order to reduce the chemical degradation under basic conditions, a longer propane aliphatic structure is more suitable than ethane structure for attaching the quaternary ammonium groups to the polymer main chain.
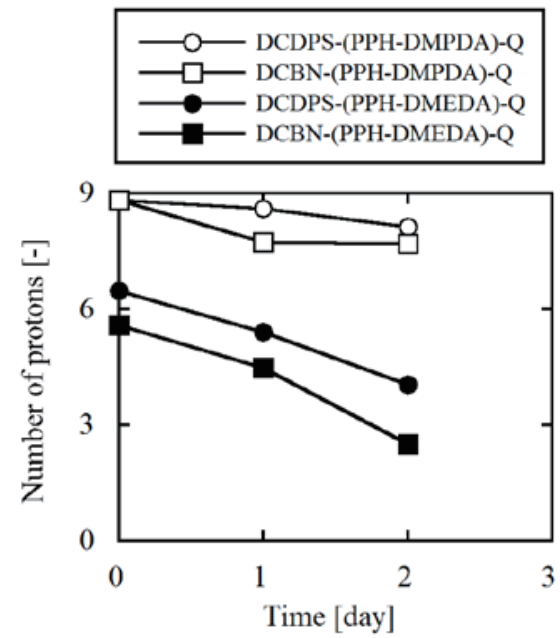

Fig.4 Degradation analysis based on the number of protons of quaternary ammonium groups.

\section{Conclusion}

A series of novel anion exchange membranes were synthesized using different $\mathrm{PPH}$ that were derivatized with different diamines (PPH-DMPDA and PPH-DMEDA) and different dihalides (DCDPS and DCBN). The PPH-DMPDA-containing copolymers were successfully quaternized with methyl iodide, and showed anionic conductivity of $\sim 10 \mathrm{mS} / \mathrm{cm}$ at $30{ }^{\circ} \mathrm{C}$. The PPH-DMEDA-containing copolymers showed rapid chemical degradation after quaternization as well as poor anionic conductivity. Precise degradation analyses were conducted in $\mathrm{NaOH}$ solution. The PPH-DMPDA-containing copolymers showed high chemical stability while the PPH-DMEDA-containing copolymers showed rapid degradation and low chemical stability. Longer propane structures seemed to be more favorable for attaching quaternary ammonium functional groups to the copolymer backbone. Thus, this result provides an additional insight for the production of new AEM structures with higher chemical stability and anionic conductivity.

Acknowledgment

The authors would like to thank the Japan Society for Science and Promotion (JSPS) for the support extended toward this research.

\section{References}

[1] B. C. H. Steele and A. Heinzel, Nature, 414, 345-352, (2001).

[2] R. Borup, J. Meyers, B. Pivovar, Y. S. Kim, R. Mukundan, N. Garland, D. Myers, M. Wilson, F. Garzon, D. Wood, P. Zelenay, K. More, K. Stroh, T. Zawodzinski, J. Boncella, J. E. McGrath, M. Inaba, K. Miyatake, M. Hori, K. Ota, Z. Ogumi, S. Miyata, A. Nishikata, Z. Siroma, Y. Uchimoto, K. Yasuda, K. I. Kimijima and N. Iwashita, Chem. Rev., 107, 3904-3951, (2007).

[3] J. R. Varcoe and R. C. T. Slade, Fuel Cells, 5, 187-200, (2005).

[4] G. F. McLean, T. Niet, S. Prince-Richard and N. Djilali, Int. J. Hydrogen Energy, 27, 507-526, (2002).

[5] K. Kordesch, V. Hacker, J. Gsellmann, M. Cifrain, G. Faleschini, P. Enzinger, R. Fankhauser, M. Ortner, M. Muhr and R. R. Aronson, J. Power Sources, 86, 162-165, (2000).

[6] K. Kneifel and K. Hattenbach, Desalination, 34, 77-95, (1980).

[7] H. Herman, R. C. T. Slade and J. R. Varcoe, J. Membr. Sci., 218, 147-163, (2003).

[8] J. R. Varcoe and R. C. T. Slade, Electrochem. Commun., 8, 839-843, (2006).

[9] G. J. Hwang and H. Ohya, J. Membr. Sci., 149, 163-169, (1998).

[10] G. J. Hwang and H. H. Ohya, J. Membr. Sci., 140, 195-203, (1998).

[11] M. R. Hibbs, M. A. Hickner, T. M. Alam, S. K. McIntyre, C. H. Fujimoto and C. J. Cornelius, Chem. Mater., 20, 2566-2573, (2008).

[12] J. H. Hao, C. X. Chen, L. Lin, L. X. Yu and W. J. Jiang, Desalination, 129, 15-22, (2000).

[13] T. W. Xu, J. Membr. Sci., 263, 1-29, (2005).

[14] T. W. Xu and W. H. Yang, J. Membr. Sci., 190, 159-166, (2001).

[15] H. W. Zhang and Z. T. Zhou, J. Appl. Polym. Sci., 110, 1756-1762, (2008).

[16] G. G. Wang, Y. M. Weng, D. Chu, D. Xie and R. R. Chen, J. Membr. Sci., 326, 4-8, (2009).

[17] M. Tanaka, M. Koike, K. Miyatake and M. Watanabe, Macromolecules, 43, 2657-2659, (2010).

[18] J. L. Yan and M. A. Hickner, Macromolecules, 43, 2349-2356, (2010).

[19] A. A. Zagorodni, D. L. Kotova and V. F. Selemenev, React. Funct. Polym., 53, 157-171, (2002).

[20] V. Neagu, I. Bunia and I. Plesca, Polym. Degrad. Stab., 70, 463-468, (2000).

[21] Q. F. Zhang, S. B. Zhang, L. Dai and X. S. Chen, J. Membr. Sci., 349, 217-224, (2010).

[22] R. C. T. Slade and J. R. Varcoe, Solid State Ionics, 176, 585-597, (2005).

(Received February 21, 2013; Accepted February 4, 2014) 